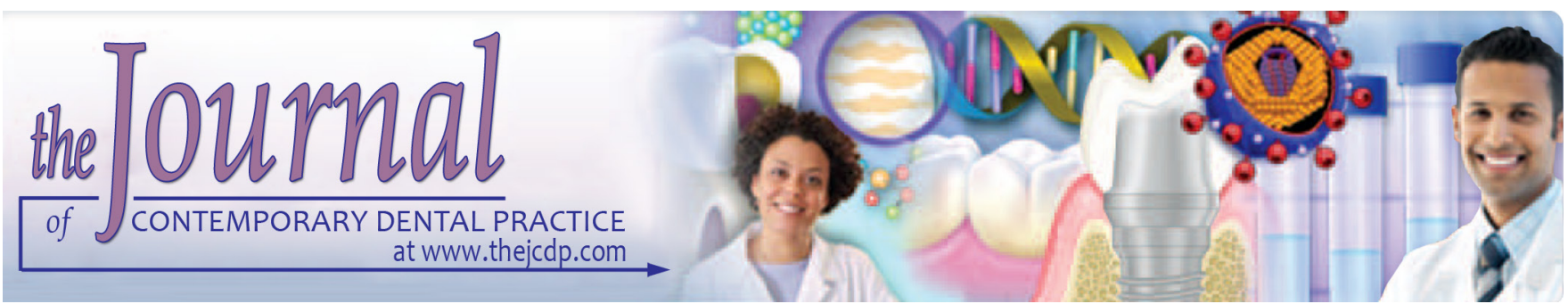

\title{
Effect of Alcohol and Tea on Solubility of Soft-liner and Polymethyl Methacrylate Resin: An In Vitro Study
}

\author{
${ }^{1}$ Rupali B Choure, ${ }^{2}$ Ashutosh Sthapak, ${ }^{3}$ Naveen S Yadav, ${ }^{4}$ Trilok Srivastava, ${ }^{5}$ Syed A Ali, ${ }^{6}$ Siddharth Dixit
}

\begin{abstract}
Aim: To evaluate solubility of soft denture liner material and acrylic denture base resin when stored in $8 \%$ and $50 \%$ concentration of alcohol and tea(with milk and green tea) at an interval of $4,7,11$ and 15 days.
\end{abstract}

Materials and methods: An in vitro study wasdone on 75 standardized samples in disk form (15 $\mathrm{mm} \times 2 \mathrm{~mm})$, each for soft-liner and acrylic denture base resin. Samples were divided into 5 groups (15 per group/per material) and stored in distilled water (A), 8\% alcohol (B), 50\% alcohol (C), tea with milk (D) and green tea $(E)$. Solubility was determined at each time interval by dividing difference of weight (taken after drying the sample in a desiccator) from day 1 divided by surface area of the specimen. For each day (i.e., 4, 7, 11 and 15),one-way analysis of variance (ANOVA) test was used to determine if the distribution of mean solubility was similar in five groups followed by post-hoc Tukey's test for pair-wise comparisons.

Results: Mean solubility of soft-liner was the highest tea with milk (D) followed by green tea (E), then $50 \%$ and $8 \%$ alcohol $(C$ and $B$ ) and was least in group $A$ at each time of measurement. Mean solubility of an acrylic resin was highest for $8 \%$ alcohol (B) and all other groups it was similar.

Conclusion: This study shows increased solubility for softliners when immersed in tea with milk, green tea, and alcohol at $8 \%$ and $50 \%$ concentration. The solubility of acrylic resin also increases at $8 \%$ alcohol concentration.

Clinical significance: Drinks/beverages used in our study are commonly consumed, the results of this study caution for restricting the frequency of intake. However, this needs to be

\footnotetext{
1,3Department of Prosthodontics, Peoples Dental Academy, Bhopal, Madhya Pradesh, India

2,4,5 Department of Orthodontics, Peoples Dental Academy, Bhopal, Madhya Pradesh, India

${ }^{6}$ Department of Orthodontics, Peoples College of Dental Sciences, Bhopal, Madhya Pradesh, India
}

Corresponding Author: Naveen S Yadav, Department of Prosthodontics, Peoples Dental Academy, Bhopal, Madhya Pradesh, India, Mobile: 9425018463, e-mail: naveensyadav@ gmail.com confirmed by in-vivo studies designed to prove the association of denture life with the consumption pattern of these drinks/ beverages.

Keywords: Acrylic resin, Alcohol, Green tea, Soft-liner, Solubility and tea with milk.

How to cite this article: Choure RB, Sthapak A, Yadav NS, Srivastava T, Ali SA, Dixit S. Effect of Alcohol and Tea on Solubility of Soft-liner and Polymethyl Methacrylate Resin: An In Vitro Study. J Contemp Dent Pract 2019;20(1):83-88.

\section{Source of support: Nil}

Conflict of interest: None

\section{INTRODUCTION}

The success of complete denture and removable partial denture depends upon esthetics, comfort, and function. Acrylic resin is most commonly utilized material in the treatment of edentulous and partially edentulous patients. Many environmental factors affect the durability of dentures. In edentulous and partially edentulous patient masticatory load and forces are transmitted through mucoperiosteal to the underlying bone. Chronic stresses lead to pathologic changes to oral tissues and results in loss of adaptation of denture. ${ }^{1,2}$ Soft lining materials are viscoelastic materials used to treat these problems. Soft denture lining materials act as a cushion and reduce functional stresses created by the masticatory load. ${ }^{3}$ They are valuable in treating patients with ridge atrophy, xerostomia, bony undercuts, abused tissues, and for denture opposing natural dentition. ${ }^{4}$

The efficiency of denture materials is based on their properties. Soft lining materials lose their resiliency and become harder after clinical use. ${ }^{5}$ When it is in clinical use, the resilient lining material is immersed in saliva and when not used, may be soaked in water or other cleansing agents. When immersed in such solutions, plasticizers and other soluble components are leached out, and water or saliva is absorbed. Water sorption and solubility, thus, 
are problems that are commonly encountered when using soft denture liners. ${ }^{5-9}$

These problems are associated with changes in structure and properties of the material that results in swelling, distortion, support of Candida albicans growth, reduced bonding to the denture base, and a hard, less resilient product over time. ${ }^{5,9}$ The aim of this study is to evaluate solubility of soft denture liner material and acrylic denture base resin when stored in $8 \%$ and $50 \%$ concentration of alcohol and tea(with milk and green tea) at an interval of 4, 7, 11 and 15 days. This is in accordance with the specification by the Council on Dental Materials and Devices as mentioned in revised American Dental Association (ADA) Specification no 12 denture base polymers. ${ }^{10}$

\section{MATERIALS AND METHODS}

This was an in vitro study conducted in the Department of Prosthodontics, Crown, and Bridge in Peoples Dental Academy, Bhopal.

\section{Mold Fabrication for Sample Preparation}

A customized three-piece acrylic mold, of dimensions $65 \mathrm{~mm} \times 40 \mathrm{~mm} \times 6 \mathrm{~mm}$ was fabricated, which contained six mild spaces of $15 \mathrm{~mm} \times 2 \mathrm{~mm}$ separated from each other by distance of $2 \mathrm{~mm}$ in length and $5 \mathrm{~mm}$ in breadth, corresponding to the dimensions of acrylic based soft denture liner disks. Four screws were placed at the corners of the mold, which helped in assembling the three pieces. This mold helps in fabrication six soft denture liner disks of dimension $15 \mathrm{~mm}$ x 2 mm (Fig. 1)

\section{Preparation of Acrylic-based Soft Denture Liner Disks}

Acrylic based soft denture liner (GC RELINETM Tissue Conditioner) was mixed in the ratio of $2.2 / 1.8 \mathrm{~g}$ by weight (first graduation on powder measure to four graduations

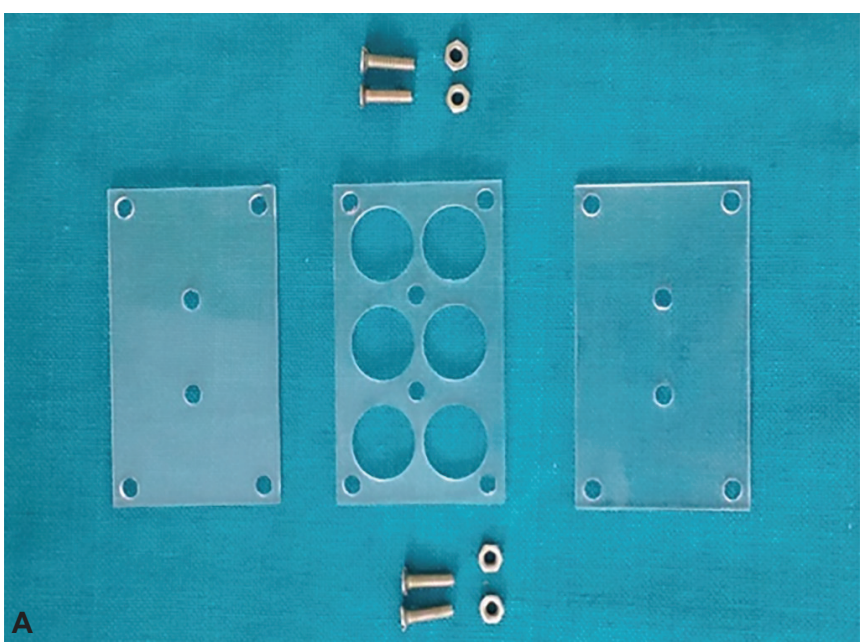

of the liquid syringe by volume) for 30 seconds. Measures of both powder and liquid were poured into a glass jar. The inner surface of mold was coated with petroleum jelly which helped easy removal of soft liner disks. The mixture was then packed into the mold spaces intermittent pressure was applied with bench press, and screws were tightened. The material was allowed to cure for 5 minutes and then immersed in cold water for complete polymerization as per the manufacturer's instructions. After polymerization mold was opened and soft liner disks were retrieved. Excess material was removed and disks were polished with the help of polishing wheel at the rate of $<6000$ RPM. Seventy-five acrylic based soft denture liner disks of dimensions $15 \mathrm{~mm} \times 2 \mathrm{~mm}$ as per ADA specifications ${ }^{10}$ were prepared.

\section{Preparation of Heat Cure Polymethylmethacrylate Denture Base Resin Disks}

Modelling wax was heated and packed in the customized mold of dimensions $65 \mathrm{~mm} \times 40 \mathrm{~mm} \times 6 \mathrm{~mm}$ same as for denture soft liner material. Screws were tightened, and intermittent pressure was applied with the help of bench press. Wax samples were retrieved and flasking was done with the help of dental plaster, and then dewaxing was done. Heat cure polymethylmethacrylate denture base resin powder and liquid were mixed in porcelain jar in the ratio of 3:1 at dough stage mold was packed with bench press and transferred it to the clamps. Samples are cured in hot water and retrieved. Excess material was trimmed with the help of acrylic bur and finishing, and polishing was carried out. Seventy-five such discs of acrylic base resin were prepared.

\section{Storage of Specimen}

Specimen of each material was divided into 5 groups containing different liquid/beverage for storage. Group A-control (distilled water), group B (8\% alcohol-strong malt beer with an ethanol content of $8 \% \mathrm{~V} / \mathrm{v})$, group $\mathrm{C}$

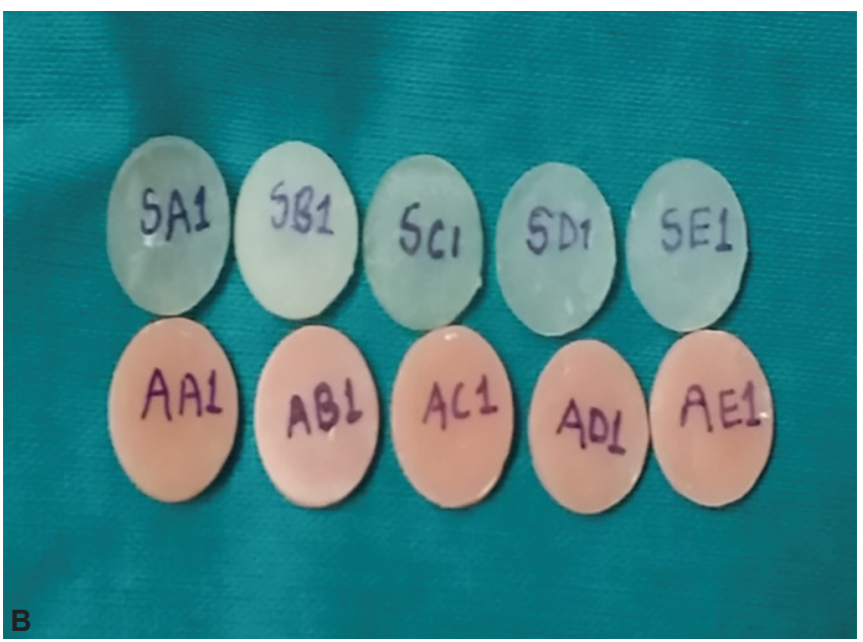

Figs 1A and B: (A) Customized 3 piece mold; (B) Fabricated specimen 
(50\% alcohol-vodka with ethanol approximately 50\% $\mathrm{ABV})$, group D (tea with milk) and group E (green tea). Each group comprised 15 specimens per group per material. Specimen were stored in $30 \mathrm{~mL}$ of respective beverage/liquid. For group D (milk and tea) and group $\mathrm{E}$ (green tea) daily replacement of beverage was done.

\section{Initial Weighing of Specimen}

All the 150 samples were dried in the desiccator containing silica gel at room temperature (Fig. 2). They were weighted daily with oriental electric precision balance machine. Disks were reweighted at regular interval of 12 hours until constant weight was achieved. All disks are found stable after 48 hours. This was considered as the initial weight of the disk $\left(W_{1}\right)$.

\section{Reweighing of Specimen}

Samples were reweighted on day 4, 7, 11 and 15 as per following procedure. All the samples were removed from the containers with the help of twisers. They were blotted dry with filter paper till no moisture was visible on their surface. Samples were reweighted using the electronic weighing machine and these weight values were considered as $\left(\mathrm{W}_{2}\right)$ after absorption values.

Then disks were blotted dry with filter paper and after weighing for sorption, were placed in the desiccator containing the silica gel for measuring the amount of soluble material loss. After this, all the five groups of denture liner disks were placed separately in a desiccator containing silica gel at room temperature and weighed daily to an accuracy of $0.001 \mathrm{~g}$ using an Oriental ${ }^{\mathrm{TM}}$ Electronic Precision Balance. This was the weight after desiccation $\left(W_{3}\right)$ (Fig. 2).

Relative solubility was determined according to the ADA specification ${ }^{10}$ no. 12 for denture basepolymers in $\mathrm{mg} / \mathrm{cm}^{2}$.

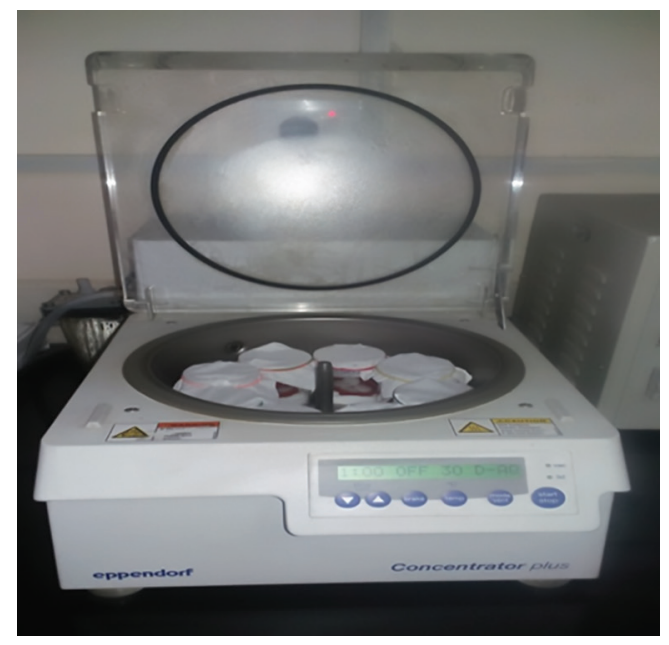

Fig. 2: Samples being conditioned in desiccator

\section{Calculation of Solubility}

- Water sorption

- Water sorption $\left(\mathrm{mg} / \mathrm{cm}^{2}\right)=\left(\mathrm{W}_{2}-\mathrm{W}_{1}\right) /$ Surface area

- $W_{2}$ : Weight after absorption, $W_{1}$ : Initial weight.

- Solubility

- Solubility $\left(\mathrm{mg} / \mathrm{cm}^{2}\right)=\left(\mathrm{W}_{1}-\mathrm{W}_{3}\right) /$ Surface area

- $W_{3}$ : Weight after desiccation, $W_{1}$ : Initial weight

- Surface area: $2 \varpi r(h+r)$

- $r$ : Radius of the acrylic-based soft denture liner disk

- $h$ : Thickness of the acrylic-based soft denture liner disk.

\section{Statistical Analysis}

For each day (i.e., 4, 7, 11 and 15), One-way ANOVA test used to test if the distribution of mean solubility was similar in five groups and then post-hoc Tukey's test was applied for pair-wise intergroup comparisons. A $p$ value $<0.05$ was considered as statistically significant. All analysis was done by using IBM-SPSS software (Version 21, IBM Corporation, New York, USA)

\section{RESULTS}

The present study comprised of 75 samples of acrylic denture base resin and 75 samples of soft denture lining material immersed in different liquids/beverages. Tables 1 and 2 shows the distribution of mean and standard deviation of solubility among different groups respectively for soft liner and acrylic base resin.

It can be observed that solubility increased among all groups with respect to time of immersion. For softliner, mean solubility of Tea and Milk group was highest on day $4(1.14 \pm 0.36)$ and this increased to $(5.21 \pm 1.14)$ on day 15 and remained significantly higher than other groups except for $50 \%$ alcohol group on day 15 (Table 1 and Graph 1). For acrylic base resin, mean solubility was highest for $8 \%$ alcohol group on day $4(0.325 \pm 0.203)$ and was significantly higher than control (group A) and green tea (group E). Its solubility increased to $(1.68 \pm 0.75)$ on day 15 and was statistically significantly higher than other groups. (Table 2 and Graph 2).

\section{DISCUSSION}

This in vitro study investigated the effect of tea and different concentration of alcohol on the solubility of the soft liner and acrylic resin. This study has shown that for soft-liner tea and milk has the highest solubility followed respectively by green tea, 50\% alcohol, $8 \%$ alcohol, and distilled water. And for acrylic base resin, only $8 \%$ alcohol had shown higher solubility than others.

According to ADA specification number 75 ( ISO 10139) provides guidelines of resilient lining materials 
Table 1: Distribution of mean solubility among different groups for GC RELINE soft-liner

\begin{tabular}{|c|c|c|c|c|}
\hline & Day-4 & Day-7 & Day-11 & Day-15 \\
\hline Material & Mean (SD) & Mean (SD) & Mean (SD) & Mean (SD) \\
\hline A (Control) & $0.501(0.257)$ & $0.795(0.380)$ & $0.826(0.633)$ & $1.210(0.700)$ \\
\hline B (8\% Alcohol) & $0.546(0.119)$ & $1.106(0.173)$ & $1.594(0.208)$ & $2.344(0.257)$ \\
\hline C (50\% Alcohol) & $0.740(0.330)$ & $1.272(0.658)$ & $2.040(0.883)$ & $2.447(1.034)$ \\
\hline $\mathrm{D}$ (Tea with milk) & $1.148(0.365)$ & $2.358(0.364)$ & $4.329(1.239)$ & $5.214(1.146)$ \\
\hline E (Green tea) & $1.120(0.157)$ & $1.608(0.265)$ & $2.199(0.306)$ & $2.921(0.238)$ \\
\hline ANOVA test $p$ value & $<0.001$ & $<0.001$ & $<0.001$ & $<0.001$ \\
\hline Post hoc test significant pairs & $\begin{array}{l}D^{*} A, B, C \\
E^{*} A, B, C\end{array}$ & $\begin{array}{l}D^{*} A, B, C, E \\
E^{*} A, B, D \\
C^{*} A\end{array}$ & $\begin{array}{l}D^{*} A, B, C, E \\
E^{*} A, D \\
C^{*} A\end{array}$ & $\begin{array}{l}D^{*} A, B, C, E \\
E^{*} A, D \\
C^{*} A, B^{*} A\end{array}$ \\
\hline
\end{tabular}

stating ideal lining material should possess no soluble component. ${ }^{10}$ If soft lining material to be effective for a long period it should be soft, complaint and dimensionally stable. ${ }^{11}$ Solubility is an important property and provides an idea of the efficiency of the soft liner as lining material.

Polymethyl methacrylate absorbs less amount of water as compared to the soft liner. Soft lining material undergoes two processes when immersed in water one is leaching of plasticizer and soluble compounds in water and absorption of water. ${ }^{6,12}$ When immersed in water it exerts a significant effect on properties of the polymer. Water ingresses through diffusion and enters to occupy space between polymer chains. This creates an expansion of mass and interferes with bonding chains of the polymer. Water acts as a plasticizer and changes its physical and dimensional properties. Water also leads o swelling and incorporation of stresses affecting bond strength of soft liner with acrylic resin. ${ }^{5}$ Along with distortion, the increased growth rate of bacteria.

Although most commonly used all soft liners shows some form of failure. In 1981 Wright found that most common problems with soft liners were due to water sorption and solubility. ${ }^{13}$

Kawano et al. found that loss of ethanol and leaching out of plasticizer causes of solubility and water sorption. ${ }^{3}$ Plasticizer exhibits large molecular weight and contributes large percentage as a component in liquid this plasticizer form slipping of polymer chains over another, and it provides the resiliency to soft lining material. Leaching of plasticizer causes loss of mass and an increase in solubility. ${ }^{6}$
The result of this comparative evaluation on solubility showed that on day 4 mean solubility of soft denture lining material across groups was statistically different $(p<0.001)$. On pairwise comparison, it was found that mean solubility of samples immersed in tea with milk and green tea was significantly higher than that of groups A to C. similarly mean solubility was different at day 7 as well. However, on day 7 mean solubility of $50 \%$ alcohol was found to be higher than control $(p=0.015)$ and mean solubility of tea with milk was higher than groups A to B, Group C and that of green tea was higher than groups $A$ and B. Mean solubility of tea with milk even higher than green tea $(p<0.001)$. The same pattern was observed on day 11 and day 15 mean solubility of even group B was higher than that of the control group.

The results for solubility of acrylic denture base materials showed that on day 4 mean solubility of acrylic was statistically significantly different and $8 \%$ alcohol group had more solubility than the control group and green tea. On day 7 every group had increased mean solubility however their distribution was not statistically different from each other $(p=0.091)$. On day $11,8 \%$ alcohol had significantly more solubility than groups $\mathrm{B}, \mathrm{D}$, and $\mathrm{E}$ and on day $158 \%$ alcohol had more mean solubility than any other group.

Solubility studies in different liquids/storage media such as artificial saliva, denture cleansers, and disinfectant solutions were reported by various researchers. ${ }^{3,6,14}$ In study by Kazanji et al. solubility of soft-liner in artificial saliva was found to be increased after one month. ${ }^{14}$ Similar finding of increased solubility of soft-liner in artificial saliva was reported by Garg et al. ${ }^{6}$

Table 2: Distribution of mean solubility among different groups for acrylic base resin

\begin{tabular}{|c|c|c|c|c|}
\hline & Day-4 & Day-7 & Day-11 & Day-15 \\
\hline Material & Mean (SD) & Mean (SD) & Mean (SD) & Mean (SD) \\
\hline A (control) & $0.045(0.093)$ & $0.280(0.101)$ & $0.442(0.019)$ & $0.266(0.192)$ \\
\hline B (8\% alcohol) & $0.325(0.203)$ & $0.622(0.376)$ & $1.155(0.567)$ & $1.687(0.758)$ \\
\hline C (50\% alcohol) & $0.207(0.230)$ & $0.560(0.513)$ & $0.768(0.515)$ & $0.975(0.696)$ \\
\hline $\mathrm{D}$ (tea with milk) & $0.207(0.230)$ & $0.325(0.203)$ & $0.443(0.334)$ & $0.560(0.513)$ \\
\hline $\mathrm{E}$ (green tea) & $0.118(0.202)$ & $0.470(0.565)$ & $0.235(0.228)$ & $0.560(0.390)$ \\
\hline ANOVA test $p$ value & 0.040 & 0.091 & $<0.001$ & $<0.001$ \\
\hline Post hoc test significant pairs & $B^{*} A, E$ & $B^{*} E$ & $B^{*} A, D, E$ & $B^{*} A, C, D, E$ \\
\hline
\end{tabular}




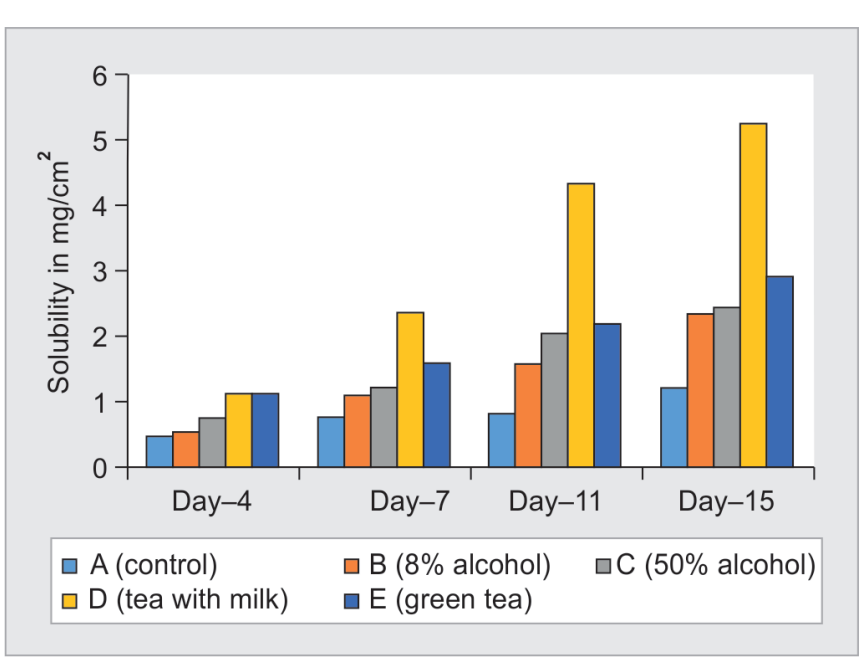

Graph 1: Comparision of mean solubility among groups for GC RELINE Soft liner

Rahmi et al. have found decrease in transverse strength of health polymerized acrylic resin with duration of black tea. ${ }^{15}$ Safari et al. tested the effect of $8 \%$ and $50 \%$ alcohol on hardness and tensile bond strength of soft-liner to the acrylic resin and found no significant interaction. ${ }^{16}$ To the best of our knowledge, this is the first study reporting solubility of soft-liner and acrylic resin in tea with milk and green tea.

In the present study,increased solubility with milk may be attributed tothe organic molecules present in it, which are responsible for the degradation and breaking of polymeric chains and leaching of soluble components. Alcohol itself acts as a plasticizer and causes solubility of denture base material and soft liner. Alcohol also provides crazing and corrosive environment and thereby weakens the denture. Higher solubility in tea than alcohol could be ascertained to the presence of phenol in tea. Phenol compounds being highly polar degrade the chemical bonds of acrylic resin and weakens the secondary polymeric chains and increases water absorption..$^{15}$

Tea with milk and green tea are commonly consumed drinks in India. Our in vitro study shows increased solubility of soft-liner and acrylic base resin when immersed in these solutions. Although drinking tea or milk gives exposure for the little duration, it poses a theoretical risk of an increase in solubility based on the results of our study. Therefore, to decrease solubility and increase the life of denture caution should be taken regarding the frequency of these beverages. However, in this context, in vivo studies to prove the association of denture life with intake pattern of these drinks/ beverages are warranted.

\section{Limitation of Study}

Oral cavity material is exposed to various composition and temperature same which could not be simulated.

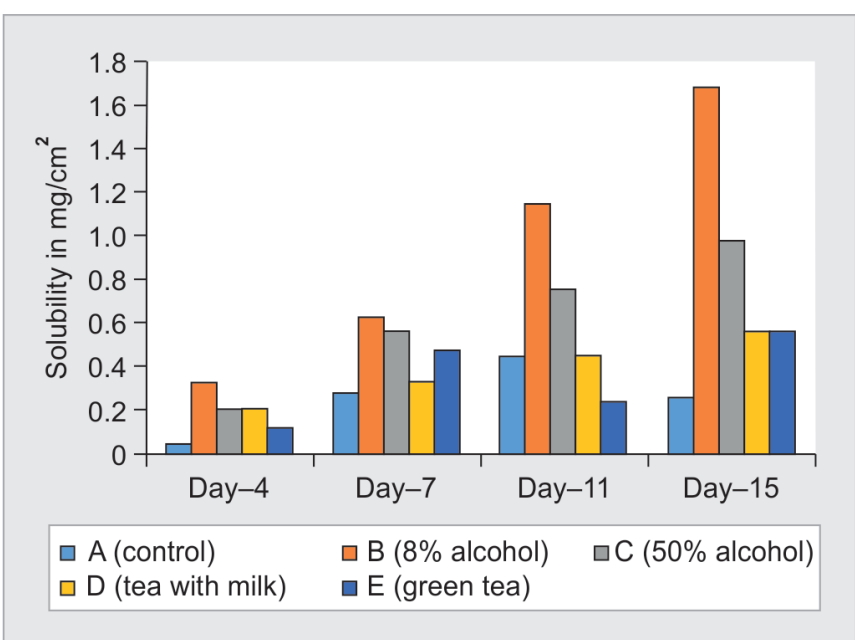

Graph 2: Comparision of mean solubility among groups for acrylic base resin

Surface area is small for the sample as compared to the intagliosurface of the denture.

\section{CONCLUSION}

From this study, it can be concluded that solubility for denture soft lining material is highest with tea with milk followed by green tea followed by $8 \%$ alcohol followed by $50 \%$ and then distilled water. Solubility for denture base resin is highest for $8 \%$ alcohol followed by $50 \%$ alcohol then tea and control.

\section{CLINICAL SIGNIFICANCE}

Drinks/beverages used in our study are commonly consumed, the results of this study caution for restricting the frequency of intake. However, this needs to be confirmed by in vivo studies designed to prove the association of denture life with the consumption pattern of these drinks/beverages.

\section{REFERENCES}

1. Kydd WL, Daly CH, Nansen D. Variation in the response to mechanical stress of human soft tissues as related to age. J Prosthet Dent. 1974 Nov;32(5):493-500.

2. Chen J, Ahmad R, Li W, Swain M, Li Q. Biomechanics of oral mucosa. J R Soc Interface [Internet]. 2015 Aug 6 [cited 2018 Sep 14];12(109).

3. Kawano F, Dootz ER, Koran A, Craig RG. Sorption and solubility of 12 soft denture liners. J Prosthet Dent. 1994 Oct;72(4):393-398.

4. Qudah S, Harrison A, Huggett R. Soft lining materials in prosthetic dentistry: a review. Int J Prosthodont. 1990 Oct;3(5):477-483.

5. Rodrigues S, Shenoy V, Shetty T. Resilient Liners: A Review. J Indian Prosthodont Soc. 2013 Sep;13(3):155-164.

6. Garg A, Shenoy KK. A comparative evaluation of effect on water sorption and solubility of a temporary soft denture liner material when stored either in distilled water, 5.25\% sodium hypochlorite or artificial saliva: An in vitro study. J Indian Prosthodont Soc. 2016;16(1):53-62. 
7. Yanikoglu ND, Duymus ZY. Comparative study of water sorption and solubility of soft lining materials in the different solutions. Dental materials journal. 2004;23(2):233-239.

8. El-Hadary A, Drummond JL. Comparative study of water sorption, solubility, and tensile bond strength of two soft lining materials. J Prosthet Dent. 2000 Mar 1;83(3):356-361.

9. Jabbal. Comparative evaluation of water sorption and solubility of two autopolymerizing soft denture liners in distilled water and artificial saliva [Internet]. [cited 2018 Sep 14].

10. Revised American Dental Association Specification No. 12 for denture base polymers. J Am Dent Assoc. 1975 Feb 1;90(2):451-458.

11. Pesun IJ, Villar A, Hodges JS, DeLong R, Lai JH, Schneider D. Development of a nondestructive compliance test for resilient denture liners. J Prosthodont Off J Am Coll Prosthodont. 2001 Jun;10(2):91-96.
12. Braden M, Wright PS, Parker S. Soft lining materials--a review. Eur J Prosthodont Restor Dent. 1995 Jun;3(4):163-174.

13. Wright PS. Composition and properties of soft lining materials for acrylic dentures. J Dent. 1981 Sep 1;9(3):210-223.

14. Kazanji MN, Watkinson AC. Soft lining materials: their absorption of, and solubility in, artificial saliva. Br Dent J. 1988 Aug 6;165(3):91-94.

15. Rahmi E, Agus Z, Putri RH. Effect of black tea on the transverse strength of heat-polymerized acrylic resin. Padjadjaran J Dent [Internet]. 2017 Nov 30 [cited 2018 Sep 21]; 29(3).

16. Safari A, Vojdani M, Mogharrabi S, Iraji Nasrabadi N, Derafshi R. Effect of Beverages on the Hardness and Tensile Bond Strength of Temporary Acrylic Soft Liners to Acrylic Resin Denture Base. J Dent. 2013 Dec;14(4):178-183. 